\title{
Yoğun Bakım Hastalarının Akut Fizyolojik Durum Değişiklikleri ile Hasta Yakınlarında Görülen Anksiyete ve Uyku Bozukluğu İlişkisi
}

\section{The Relationship Between Anxiety and Sleep Disturbances in Relatives of Patients with Acute Physiological Status Changes in Intensive Care Unit}

Bekir Opuş ${ }^{1}$,

Funda Gök²,

Alper Kılıçaslan ${ }^{3}$,

Alper Yosunkaya ${ }^{2}$

${ }^{1}$ Beyhekim Devlet Hastanesi, Anesteziyoloji ve Reanimasyon Kliniği, Konya, Türkiye. ${ }^{2}$ Necmettin Erbakan Üniversitesi, Meram Tıp Fakültesi, Anesteziyoloji ve Reanimasyon $A D$, Yoğun Bakım BD, Konya, Türkiye.

${ }^{3}$ Necmettin Erbakan Üniversitesi, Meram Tıp Fakültesi, Anesteziyoloji ve Reanimasyon $A D$, Konya, Türkiye.

Geliş Tarihi/Received: 26 Ağustos 2020 Kabul Tarihi/Accepted: 1 Ekim 2020

Yazışma Adresi: Funda Gök, Necmettin Erbakan Üniversitesi, Meram Tıp Fakültesi, Anesteziyoloji ve Reanimasyon Anabilim Dalı, Yoğun Bakım Bilim Dalı, Konya, Türkiye e-posta: fundagok@gmail.com

\section{ORCID}

Bekir Opuş

https://orcid.org/0000-0002-4572-4235

Funda Gök

https://orcid.org/0000-0002-4968-1420

Alper Kılıçaslan

https://orcid.org/0000-0002-2570-5854

Alper Yosunklaya

https://orcid.org/0000-0003-2525-4480

\begin{abstract}
Öz
Amaç: Yoğun bakım ünitesinde (YBÜ) yatan hastaların genel durum ciddiyeti ile aile üyelerinde görülen akut stres semptomları arasındaki ilişkinin incelenmesi amaçlandı.

Hastalar ve Yöntem: Yerel etik kurul onayı ve yazılı bilgilendirilmiş onam alındıktan sonra, yoğun bakımda yatan 60 hastanın 2014-2015 yıllarında 2 yıllık periyotta bu prospektif tanımlayıcı çalışma gerçekleştirildi. Hastaların klinik özellikleri (APACHE II skoru) kaydedildi. Birinci derece aile üyelerinin demografik verileri ve durumluluk-süreklilik kaygı ölçeği (DSKÖ) ile Pittsburgh uyku kalitesi indeksi (PUKi) skorları YBÜ'ye kabul edildikten sonraki 24 saat içinde ve 21. Gün kaydedildi.

Bulgular: APACHE 2 ile DKÖ skorları arasında 1. günde orta düzeyde $(r=0.477), 21$. günde güçlü $(r=0.503)$ düzeyde korelasyon saptandı $(p<0.05)$. APACHE 2 skoru ile PUKI arasında 21. günde orta düzeyde $(r=0.503)$ anlamlı korelasyon bulundu. DKÖ skorları değerlendirildiğinde 1. gün cinsiyetler arasında fark yoktu. Her iki cinsiyette 21. günde DKÖ skorlarında artış saptandı, bu artış kadınlarda daha yüksekti $(p=0.003)$. PUKI değerlerinde 1. günde istatistiksel olarak bir fark bulunmazken, 21. günde her iki cinsiyette artış saptanmıştır $(p<0.001)$. Uyku bozukluğundaki artış kadınlarda daha fazladır $(p=0.008)$. Yakınlık derecesine göre analiz edildiğinde DKÖ değerleri anne ve babalarda hem 1. hemde 21. günde daha yüksek idi $(p<0.001)$. Grup içi değerlendirmede anne ve babanın kaygılarının gün geçtikçe arttığı gözlendi $(p<0.05)$.

Sonuç: Hastanın akut fizyolojik durumu ile kaygı düzeyi ve uyku kalitesi arasında zaman ilerledikçe giderek artan düzeyde ilişki saptanmıştır.
\end{abstract}

Anahtar Kelimeler: Yoğun bakım, hasta yakını, anksiyete ve uyku bozukluğu

\section{Abstract}

Aim: The aim of this study was to investigate the relationship between the seriousness of the clinical condition of the patients in intensive care unit (ICU) and acute stress symptoms of family members. Patients and Methods: After local ethic committe approval and written informed consent was obtained, we carried out a prospective, descriptive study at a universty hospital during the two year period (20142015). Clinical characteristics (APACHE II score) of patients was recorded. First degree relatives of 60 ICU patients provided demographic data and completed the State-Trait Anxiety Inventory Form (STAI) and Pittsburgh Sleep Quality Index (PSQI) within $24 \mathrm{~h}$ of ICU admission and 21 days later.

Results: There were a moderate correlation between APACHE 2 and STAI scores on day $1(r=0.477)$ and a strong correlation $(r=0.503)$ on day $21(p<0.05)$. A moderate correlation $(r=0.503)$ was found between APACHE 2 score and PSQI on day 21. STAI scores were not different between genders on day 1 . There was an increase in both sexes in STAI scores on day 21), and the scores ere significantly more in females $(p=0.003)$. While there was no statistically significant difference in PSQI scores on day 1 , an increase was found in both sexes on day 21 ( $p<0.001)$. Female family members had more sleep disturbances $(p=0.008)$. STAI scores were higher in both mothers and fathers on day 1 and $21(p<0.001)$.

Conclusions: An increasing relationship was determined between patients' acute physiological condition and anxiety with sleep quality level of patients' relatives as the time passed.

Key words: Intensive Care Unit, the relatives of the patient, anxiety and sleep disorders.
Atıf yapmak için: Opuş B, Gök F, Kılıçaslan A, Yosunkaya A. Yoğun Bakım Hastalarının Akut Fizyolojik Durum Değişiklikleri ile Hasta Yakınlarında Görülen Anksiyete ve Uyku Bozukluğu İlişkisi. Selcuk Med J 2020;36(4): 333-337
Açıklama: Yazarların hiçbiri, bu makalede bahsedilen herhangi bir ürün,
aygıt veya ilaç ile ilgili maddi çıkar ilişkisine sahip değildir. Araştırma,
herhangi bir dış organizasyon tarafından desteklenmedi. Yazarlar çalışmanın
birincil verilerine tam erişim izni vermek ve derginin talep ettiği takdirde
verileri incelemesine izin vermeyi kabul etmektedirler.

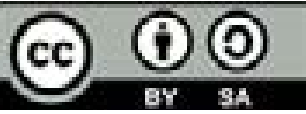




\section{GíRiş}

Yoğun bakım ünitesinde (YBÜ) tedavi gören hastalar, uzun süre hastanede kalma, morbidite ve mortalite gelişme riski en yüksek olan kritik hastalardır $(1,2)$. Bu hastaların yakınlarında, hastalarını kaybetme korkusu başta olmak üzere birçok neden, ileri düzeyde kaygı ve uyku bozukluğu oluşturabilir $(3,4)$. Çoğunlukla bilinçleri kapalı ve daha fazla bakıma intiyacı olan bu hastaların yakınları ile iletişimin kurulması ve sürdürülmesi, sağlık çalışanları açısından da zorluklar taşır (5). Sağlık profesyonellerinin daha çok hastanın intiyaçları için eğitilmeleri ailenin durumunun gözardı edilmesine neden olur $(6,7)$. Kritik hastaların aile üyeleri genellikle artan düzeyde kaygıya sahiptirler ve yaşam kaliteleri azalır (8). Özellikle hastalara uygulanacak girişim ve tedaviler ile ilgili yakınlarının verecekleri kararlar kaygı düzeyini artırır $(9,10)$. Yoğun bakım ünitelerinde takip edilen hasta yakınları psikososyal yönden desteklenmelidirler.

Yoğun bakım hasta yakınlarında görülebilen psikolojik bozukluklar anksiyete, depresyon, fiziksel işlev bozukluğu, uyku bozuklukları ve sosyal izolasyondur (11). Uyku bozukluğu ve anksiyete ise strese azalmış tolerans, sinirlilik, azalmış dikkat, azalan bağışıklık fonksiyonu ve karar verme yeteneğinde kötüleşme gibi değişikliklere neden olabilir (12). Birçok çalışmada, hastalarda görülen kaygı ve uyku bozukluğu incelenmiş olmasına rağmen yoğun bakımda tedavi gören hastaların aile üyelerinin anksiyete ve uyku bozukluklarının ayrıntılı olarak değerlendirildiği çalışmalar az sayıdadır. Bu çalışmada, yoğun bakım hastalarının birinci derece yakınlarında görülen anksiyete ve uyku bozukluğu semptomlarının cinsiyet, öğrenim düzeyi, yakınlık durumları ve hastaların akut fizyolojik durum değişikliği ile ilişkisinin araştırılması amaçlanmıştır.

\section{HASTALAR VE YÖNTEM}

$\mathrm{Bu}$ prospektif, tanımlayıcı, gözlemsel çalışma yerel etik kurul onayı (694/2014) alındıktan sonra, üniversite hastanesi YBÜ tedavi gören 60 hasta yakını ile gerçekleştirildi. YBÜ'nde en az 48 saat kalması beklenen hastaların, 18 yaş üzerinde olan birinci derece yakınlarına çalışma hakkında bilgi verilerek yazılı ve sözlü onamları alındı. Anksiyete ve/veya uyku bozukluğu tedavisi alan, kognitif ve ruhsal bozukluğu olan hasta yakınları çalışmaya dahil edilmedi. Hasta yakınlarının demografik bilgileri, yakınlık dereceleri, eğitim düzeyleri kaydedildi. Başvuru ve YBÜ'nde kalış sırasında hastaların fizyolojik değişkenleri, yaş ve kronik sağlık değerlendirmelerini içeren APACHE
(Acute Physiology and Chronic Health Evaluation) II skorları hesaplandı (13). Hasta yakınları çalışmaya katılmadan önce hastalarının durumu hakkında yoğun bakım uzmanı tarafından APACHE II skorları dikkate alınarak bilgilendirildi. Üç bölümden oluşan anket için ilk değerlendirme yoğun bakıma kabulden 24 saat sonra, ikincisi ise uyku bozukluğunu daha iyi değerlendirmek için üç hafta sonra (21. gün) aynı hekim tarafından uygulandı.

Birinci ve ikinci bölümde hasta yakınlarının anksiyete düzeylerini belirlemek için DurumlukSürekli Kaygı Ölçeği (State-Trait Anxiety Inventory=STAI) kullanıldı $(14,15)$. Durumluk Kaygı Ölçeği (DKÖ); bireyin belli bir anda belli bir koşulda kendini nasıl hissettiğini belirlerlerken, Sürekli Kaygı Ölçeği (SKÖ); bireyin içinde bulunduğu durum ve koşullardan bağımsız olarak kendini nasıl hissettiğini belirlemektedir. STAI, herbiri 20 maddelik olumsuz ve olumlu duyguları değerlendiren soruları içerir. Her iki alt ölçeğin puanları ayrı ayrı toplanarak, 20-80 (anksiyete artışı ile puan yükselir) arasında toplam puanlar elde edilir. Üçüncü bölümde ise uyku kalitesini miktarını, uyku bozukluğunun varlığını ve şiddetini ölçmek için Pittsburgh Uyku Kalite İndeksi (PUKI) kullanıldı (16). PUKI 0-3 arasında puanlananan toplam 19 soru ile uykunun kalitesini, gecikmesini, süresini, verimliliğini, gündüz işlerine etkisini ve uyku ilacı kullanımının değerlendirildiği yedi ögeden oluşmaktadır. Toplam skor 0-21 arasında değişir ve yüksek değerler uyku bozukluğu ile birliktedir.

Çalışmada hastanın genel durumunu gösteren APACHE II skoru ile hasta yakınlarının kaygı ve uyku bozuklarını ölçen DKÖ, SKÖ, PUKI skorları arasında korelasyon olup olmadığı araştırıldı. Ek olarak yakınlık derecesi, cinsiyet ve eğitim durumunun kaygı ve uyku kalitesine etkisi değerlendirildi.

\section{Istatistiksel Analiz}

İstatistiksel analiz için SPSS 18.0 programı kullanıldı. kategorik ölçümler sayı ve yüzde olarak, sayısal ölçümlerse ortalama ve standart sapma olarak özetlendi. Farklı iki grup Mann Whitney $U$ ve ikiden daha fazla grup Kruskal Wallis testi ile karşılaştırıldı. Ölçek skorları arasındaki korelasyonlar için Spearman korelasyon testi kullanıldı. $\mathrm{P}<0.05$ anlamlı kabul edildi.

\section{BULGULAR}

Çalışmaya yoğun bakımda yatan 60 hasta yakını alınmış, fakat dahil edilme kriterleri uymadığı için 13 hasta yakını çalışma dışı bırakılmış ve 47 katılımcı ile çalışma sonlandırılmıştır. Çalışmaya dahil edilen 
Tablo 1. Hasta yakınlarının demografik özellikleri

\begin{tabular}{lc}
\hline Demografik Özellik & Ort \pm SD (n=47) \\
\hline Yaş & $45 \pm 9,5(29-68)$ \\
Cinsiyet (E/K) & $26(55,3) / 21(44,7)$ \\
Eğitim Durumu & $\mathbf{n}(\%)$ \\
İlkokul & $12(25,5)$ \\
Ortaokul & $3(27,7)$ \\
Lise & $15(31,9)$ \\
Yüksekokul & $7(14,9)$ \\
Yakınlık Derecesi & $\mathbf{n}(\%)$ \\
Kardeş & $5(10,6)$ \\
Eş & $19(40,4)$ \\
Oğul & $7(14,9)$ \\
Kızı & $4(8,5)$ \\
Annesi & $7(14,9)$ \\
Babası & $5(10,6)$ \\
\hline Veriler ortalama \pm standart sapma (SD) ve hasta sayısı (\%) olarak \\
sunulmuştur.
\end{tabular}

hasta yakınlarının sosyo-demografik özellikleri (yaş, cinsiyet, öğrenim durumları) Tablo 1' de sunulmuştur. APACHE II skoru ile DKÖ skoru arasında 1. günde orta düzeyde $(r=0,447, p=0,001) 21$. günde güçlü $(r=0,503, p=0,000)$ düzeyde pozitif yönde korelasyon mevcuttur. APACHE II skoru ve SKÖ arasında herhangi bir korelasyon ve anlamlı fark görülmemiştir. APACHE II skoru ile PUKİ skoru arasında 21. günde orta düzeyde $(r=0,325, p=0,026)$ pozitif yönde anlamlı korelasyon saptanmıştır (Tablo 2).

Yakınlık derecesine göre analiz edildiğinde DKÖ değerleri anne ve babalarda hem 1. hemde 21. günde daha yüksek idi $(p<0,001)$. Grup içi değerlendirmede anne ve babanın kaygılarının gün geçtikçe arttığı gözlendi $(p<0,05)$. Hasta yakınlarına 1. gün uygulanan SKÖ skorlarında yakınlık düzeylerine göre istatistiksel olarak anlamlı fark yok idi $(p>0,05)$. PUKI skorlarında 1.ve 21. günde yakınlık derecesine göre istatistiksel olarak anlamlı farklar saptandı $(p=0,019, p=0,000)$. PUKİ skorlarında grup içi yakınlık derecesine göre 1. ve 21 gün değerlendirildiğinde anne, baba, eş, kardeş ve kız evlatta uyku bozukluğu gün geçtikçe
Tablo 2. APACHE-2 skorları ve ölçekler arası korelasyon

\begin{tabular}{|c|c|c|c|}
\hline & & $\begin{array}{c}\text { Korelasyon } \\
\text { Katsayısı }\end{array}$ & P değeri \\
\hline DKÖ/APACHE-2 & 1.gün & 0,477 & 0,001 \\
\hline DKÖ/APACHE-2 & 21.gün & 0,503 & 0,000 \\
\hline SKÖ/APACHE-2 & 1.gün & 0,232 & 0,075 \\
\hline PUKI/APACHE-2 & 1.gün & 0,073 & 0,325 \\
\hline PUKI/APACHE-2 & 21.gün & 0,264 & 0,026 \\
\hline
\end{tabular}

DKÖ= Durumluk kaygı ölçeği SKÖ= Süreklilik kaygı ölçeği, PUKI= Pittsburgh uyku kalitesi indeksi

artmakta iken $(p<0,05)$, oğulda uyku bozukluğu saptanmamaştır ( $p>0,05$; Tablo3). Hasta yakınlarına 1.ve 21. günlerde uygulanan DKÖ skorları cinsiyete göre analiz edildiğinde 1. günde istatistiksel olarak bir fark bulunmazken, 21. günde kadınlarda daha yüksekti $(p=0,003)$. Grup içi karşılaştırmada, erkeklerde bir fark bulunmazken, kadınlarda 21. günde artış saptandı ( $p<0,001)$.

Hasta yakınlarına 1. günde uygulanan SKÖ değerlendirilmesinde cinsiyetler arasında istatistiksel olarak anlamlı bir fark bulunmamıştır $(p>0,05)$. PUKİ değerleri cinsiyete göre analiz edildiğinde 1. günde istatistiksel olarak bir fark bulunmazken, 21. günde her iki cinsiyette artış saptanmıştır $(p<0,001)$. Uyku bozukluğundaki artış kadınlarda daha fazladır $(p=0,008)$ (Tablo 4). Eğitim düzeylerine göre analiz edildiğinde, farklı seviyede eğitim almış hasta yakınlarında ölçülen 1. ve 21. gün DKÖ, SKÖ skorları ve PUKI değerleri arasında istatistiksel olarak anlamlı bir fark bulunmamıştır $(p>0,05)$.

\section{TARTIŞMA}

$\mathrm{Bu}$ çalışmada yoğun bakımda tedavi gören hastaların genel durumları ile, bu dönemde yakınlarında ortaya çıkan anksiyete, kaygı düzeyleri ve uyku bozukluklarının arasındaki ilişki ve bu ilişkiye yakınlık derecesi, cinsiyet, ve eğitim düzeyinin etkileri araştırıldı. Hastaların akut fizyolojik durumu ile hasta

Tablo 3. Aile bireylerinin yakınlık dercesi ile kaygı ve uyku düzeyinin erken ve geç dönemde ilişkisi

\begin{tabular}{|c|c|c|c|c|c|c|c|}
\hline & $\begin{array}{c}\text { Anne } \\
\text { Ort } \pm S D \\
(n=7)\end{array}$ & $\begin{array}{c}\text { Baba } \\
\text { Ort } \pm S D \\
(n=5)\end{array}$ & $\begin{array}{c}\text { Eş } \\
\text { Ort } \pm \text { SD } \\
(n=19)\end{array}$ & $\begin{array}{c}\text { Kardeş } \\
\text { Ort } \pm S D \\
(n=5)\end{array}$ & $\begin{array}{c}\text { KIZI } \\
\text { Ort } \pm S D \\
(n=4)\end{array}$ & $\begin{array}{c}\text { Oğlu } \\
\text { Ort } \pm \text { SD } \\
(n=7)\end{array}$ & $\begin{array}{l}\text { p } \\
\text { değeri }\end{array}$ \\
\hline DKÖ 1.gün & $57,00 \pm 5,16 \#$ & $55,20 \pm 7,43 \#$ & $50,42 \pm 8,90 \#$ & $45,00 \pm 4,18 \&$ & $47,00 \pm 5,47 \&$ & $40,71 \pm 2,43$ & $0,001^{*}$ \\
\hline DKÖ 21.gün & $64,43 \pm 3,82 \&$ & $58,60 \pm 7,30 \&$ & $50,74 \pm 8,64$ & $40,80 \pm 2,38$ & $45,50 \pm 3,31$ & $40,71 \pm 7,43$ & 0,000 * \\
\hline SKÖ 1.gün & $38,86 \pm 2,67$ & $38,80 \pm 5,49$ & $39,26 \pm 3,97$ & $39,60 \pm 2,07$ & $37,75 \pm 3,59$ & $36,14 \pm 2,03$ & 0,479 \\
\hline PUKİ 1.gün & $3,71 \pm .75 \#$ & $4,80 \pm .44 \#$ & $4,16 \pm 1,30 \#$ & $2,80 \pm .837$ & $3,75 \pm .50$ & $3,14 \pm .69$ & $0,019^{*}$ \\
\hline PUKİ 21.gün & $7,14 \pm 1,77 \&$ & $6,20 \pm 1,92 \&$ & $5,32 \pm 1,56 \&$ & $3,80 \pm .83 \&$ & $4,0 \pm 0,81 \&$ & $3,43 \pm .78$ & 0,000 * \\
\hline
\end{tabular}

DKÖ= Durumluk kaygı ölçeği SKÖ= Süreklilik kaygı ölçeği, PUKI= Pittsburgh uyku kalitesi indeksi, *yakınlık derecesine göre ileri düzeyde anlamlı fark, \# grup içi yakınlık derecesine göre anlamlı fark, \& grup içi yakınlık derecesine göre 1. ve 21. gün arası anlamlı fark 
Tablo 4. İki Grubun Laboratuvar ve Klinik Bulguları *

\begin{tabular}{llll}
\hline & Erkek(n=26) & Kadın(n=21) & $\mathbf{P}$ \\
\hline DKÖ 1. gün & $48,04 \pm 9,57$ & $51,52 \pm 6,3$ & 0,159 \\
DKÖ 21. gün & $46,73 \pm 9,56$ & $55,43 \pm 9,47 \#$ & $0,003^{*}$ \\
SKÖ 1. gün & $38,54 \pm 4,16$ & $38,67 \pm 2,76$ & 0,904 \\
PUKi 1. gün & $3,73 \pm 1,07$ & $3,95 \pm 1,16$ & 0,502 \\
PUKI 21. gün & $4,50 \pm 1,53 \#$ & $5,90 \pm 1,92 \#$ & $0,008^{*}$
\end{tabular}

DKÖ= Durumluk kaygı ölçeği SKÖ= Süreklilik kaygı ölçeği, PUKI= Pittsburgh uyku kalitesi indeksi, ${ }^{*}$ cinsiyete göre anlamlı fark, \# 1. ve 21. gün arası grup içi anlamlı fark

yakınlarının anksiyete düzeyi arasında zaman geçtikçe artan bir ilişki belirlendi. Durumluk kaygı düzeyinin ve uyku bozukluğunun kadınlarda gün geçtikte arttığı tespit edildi. Aynı şekilde anne ve babalarda kaygı düzeyleri daha yüksekti ve zamanla artış mevcuttu. Aile bireylerinde genel olarak uyku bozukluğunun da gün geçtikçe arttığı saptandı. Yoğun bakım hasta yakınlarının gereksinimleri ilk kez Molter tarafından araştırılmış ve ailelerin bilgiye, desteğe, rahatlamaya ve hastaya yakın olmaya ihtiyaç duydukları belirtilmiştir (17). Aile üyelerinin ziyaretlerinin kısıtlanması, yeterince bilgilendirilmemesi, stres, anksiyete ve uyku bozukluğu ile sonuçlanabilir $(18,19)$.

Yoğun bakımda tedavi gören hasta yakınlarında anksiyete, depresif belirtiler, post-travmatik stres bozukluğuna cinsiyetin etkileri birçok çalışmada araştırılmıştır. Çalışmaların çoğunluğunda cinsiyetin stres yanıtı ile ilgili olduğunu, kadınlarda erkeklere göre ciddi anksiyete ve depresyon semptomları görüldüğü bildirilmiştir $(9,10,20-22)$. Buna karşın yoğun bakım ünitesinde hasta yakınlarında anksiyete ve depresyon semptomlarını belirlemek amacı ile yapılan çalışmaların bazılarında hem anksiyete hem de depresyonun cinsiyet ile ilişkisinin olmadığı belirtilmiştir (23-25). Bu çalışmada DKÖ skorları cinsiyete göre değerlendirildiğinde 21. günde kadınlarda daha yüksekti. Çalışmamızın sonuçlarına göre yoğun bakım yatış süresi uzadıkça kadınlarda kaygı şiddeti daha fazla artmaktadır. Düşük eğitim seviyesininin hasta ile ilgili verilen bilgileri anlamada ve gerekli kararları vermede yetersizlik ile ilgili olabileceği, bu durumun ise yüksek stres seviyesi ile sonuçlanabileceği bildirilmiştir $(10,25-$ 27). Ancak bu çalışmada yoğun bakımda tedavi gören hasta yakınlarının eğitim düzeylerinin, kaygı ve uyku bozuklukları ile ilişkisi olmadığı gösterildi. Çalışmamızda önceki çalışmalardan farklı sonuç elde edilmesinin nedeninin, hasta yakınlarına yeterli zaman ayrılması, ayrıntılı ve anlaşılabilir şekilde bilgilendirme yapılması olduğu kanaatindeyiz.
Hastaya yakınlık derecesi, akut stres ve kaygı seviyesini belirleyen en önemli faktörlerden biridir. Bir çok çalışmada eşleri hakkında karar vermek zorunda olan hasta yakınlarında stres gelişimi en yüksek düzeyde tepit edilmiştir $(9,10,26)$. Diğer yandan hasta yakınlarındaki anksiyete ile yakınlık derecesi arasında ilişki olmadığını bildiren çalışma da mevcuttur (24). Bu çalışma sonuçlarına göre, hastanın durum değişikliğinden kaynaklanan kaygılanma annebabada daha belirgindi ve anne-babanın kaygılarının gün geçtikçe arttığı gözlemlendi.

Hastaları ile ilgili yaşam süresini ve kalitesini etkileyecek kararları vermek aile bireylerinde kaygı düzeyini artırır (9). Anderson ve ark. (24) yaptıkları çalışmada, hasta hakkında verilen bilgilerin yeteri kadar anlaşılmamasının, hasta yakınlarında daha çok strese ve hasta ile ilgili kararlara daha az katılmalarına neden olduğu gözlemlenmiştir. Yoğun bakım hastası ile ilgili hasta yakınlarını doğru ve açık olarak bilgilendirme son derece önem taşır. Hastanın genel durum ciddiyeti ise akut fizyolojik parametreleri objektif olarak değerlendiren skorlama sistemleri ile belirlenebilir $(10,28,29)$. Bu çalışmalarda akut fizyolojik skorlamalarında artış var ise yakınlarında anksiyete ve depresyon semptomlarında artış olduğu gösterilmiştir. Çalışmamızda hastaların fizyolojik durumlarını APACHE II skorlaması ile değerlendirdik. Diğer çalışmalar ile uyumlu olarak bu çalışmada hastaların APACHE 2 ile durumluk kaygı skorları aralarında özellikle gün geçtikçe anlamlı korelasyon saptandı.

Kronik hastalığı olan bireylerde uyku kalitesinin bozulduğu bilinmektedir (30). Benzer bir durum yoğun bakımda yatan hastaların yakınlarında da gözlenmekte, uyku kalitesi kötüleşirken, miktarı azalmaktadır (31,32). Van Horn ve ark. (33) çalışmasında aile üyeslerinin \% 70'inde daha kötü uyku kalitesi ve \% 80'inde daha az uku zamanı saptanmıştır. Bu çalışmada kadın ve erkek hasta yakınlarına ilk gün uygulanan PUKI skorları arasında fark olmadığı, 21. günde her iki cinsiyette artış olmasına rağmen kadınlarda daha fazla uyku bozukluğu geliştiği tespit edildi. Ek olarak hastaların APACHE 2 ile uyku bozukluğu arasında zaman geçtikçe artan bir ilişki belirlendi. Bu çalışmanın kısıtlayıcı faktörü tek merkezde ve kısıtlı sayıda katılımcı ile yapılmış olmasıdır. Sonuç olarak, yoğun bakımda hastalarının yakınlarında kaygı ve uyku bozukluğu gibi semptomlar görülebilir. Bu kaygılanma ve uyku bozukluğu düzeyi gün geçtikçe özellikle anne-babalarda ve kadınlarda daha fazla artmaktadır. Yeterli sürede, ayrıntılı ve 
anlaşılabilir bilgilendirme yapıldığında, eğitim düzeyi ve kaygılanma arasında ilişki saptanmamıştır. Hastanın akut fizyolojik durumu ile yakınlarının kaygı düzeyi ve uyku bozukluğu arasında zaman ilerledikçe artan ilişki olabilir. Bu bilgiler ışığında kaygılanma ve uyku bozukluğunun nedenlerini araştıran daha fazla sayıda hasta yakını ile yapılmış çalışmalara ihtiyaç vardır.

Çıkar Çatışması: Çalışmada herhangi bir çıkar çatışması yoktur.

Finansal Çıkar Çatışması: Çalışmada herhangi bir finansal çıkar çatışması yoktur.

Yazışma Adresi: Funda Gök, Necmettin Erbakan Üniversitesi, Meram Tıp Fakültesi, Anesteziyoloji ve Reanimasyon Anabilim Dalı, Yoğun Bakım Bilim Dalı, 42080 Konya, Türkiye.

e-mail: fundagok@gmail.com

\section{KAYNAKLAR}

1. Cheng $\mathrm{DCH}$, Byrick RJ, Knobel E. Structural models for intermediate care areas. Crit Care Med 1990;27:2266-71.

2. Akpir K. Yoğun bakım temel ilkeleri. Tüzüner $F$, editör. Anestezi, yoğun bakım, ağrı. 1.baskı. Ankara: Nobel Tıp Kitabevi 2010;1199-208.

3. Foss KR, Tenholder MF. Expectations and needs of persons with family members in an Intensive Care Unit as opposed to a general ward. South Med J 1993;86:380-4

4. Leske JS. Interventions to decrease family anksiety. Crit Care Nurse 2002; 22: 61-5.

5. Mollaoğlu M. Kritik bakım ünitelerinin duyusal girdilere etkileri ve hemşirelik girişimleri. Yoğun Bakım Hemşireleri Dergisi 1997;1:11-2.

6. Kleinpell RM, Powers MJ. Needs of family members of intensive care unit patients. Appl Nurs Res 1992;5:2-8.

7. Plowright $\mathrm{Cl}$. Needs of visitors in the intensive care unit. $\mathrm{Br} \mathrm{J}$ Nurs 1995;4:1081-3.

8. Wartella JE, Auerbach SM, Ward KR. Emotional distress, coping and adjustment in family members of neuroscience intensive care unit patients. J Psychosom Res 2009;66:5039.

9. Pochard F, Darmon M, Fassier T, et al. Symptoms of anxiety and depression in family members of intensive care unit patients before discharge or death. A prospective multicenter study. J Crit Care 2005;20:90-6.

10. Paparrigopoulos T, Melissaki A, Efthymiou A, et al. Shortterm psychological impact on family members of intensive care unit patients. J Psychosom Res 2006; 61:719-22.

11. Hickman RL Jr, Douglas SL. Impact of chronic critical illness on the psychological outcomes of family members. AACN Adv Crit Care 2010;21:80-91.

12. Davidson JE, Jones C, Bienvenu OJ. Family response to critical illness: Postintensive care syndrome-family. Crit Care Med 2012;40:618-24.

13. Knaus WA, Wagner DP, Draper EA. Development of APACHE. Crit Care Med 1989;17:181-5.

14. Spielberger CD, Gorsuch RL, Lushene R, et al. Manual for the State-Trait Anxiety Inventory. Consulting Psychologists Press: Palo Alto, CA, 1983.
15. Aydemir Ö, Köroğlu E. Psikiyatride kullanılan klinik ölçekler. 4th ed. Ankara: Hekimler Yayın Birliği; 2009.

16. Buysse DJ, Reynolds CF, Monk TH. The pittsburgh sleep quality index: A new instrument for psychiatric practice and research. Psychiatry Res 1989;2:193-213.

17. Molter NC. Needs of relatives of critically ill patients: A descriptive study. Heart Lung 1979;8:332-9.

18. Lange $P$. Family stress in the intensive care unit. Crit Care Med 2001;29:2025-6.

19. Marco L, Bermejillo I, Garayalde N, et al. Intensive care nurses beliefs and attitudes towards the effect of open visiting on patients, family and nurses. Nurs Crit Care 2006; 11:33-41.

20. Brewin CR, Andrews B, Rose S, et al. Acute stress disorder and posttraumatic stress disorder in victims of violent crime. Am J Psychiatry 1999;156:360-6.

21. Lins Fumis RR, Deheinzelin D. Family members of critically ill cancer patients: Assessing the symptoms of anxiety and depression. Intensive Care Med 2009;35:899-902.

22. McAdam JL, Dracup KA, White DB, et al. Symptom experiences of family members of intensive care unit patients at high risk for dying. Crit Care Med 2010;38:1078-85.

23. Anderson WG, Arnold RM, Angus DC, et al. Posttraumatic stress and complicated grief in family members of patients in the intensive care unit. J Gen Intern Med 2008;23:1871-6.

24. Anderson WG, Arnold RM, Angus DC, et al. Passive decisionmaking preference is associated with anxiety and depression in relatives of patients in the intensive care unit. J Crit Care 2009;24:249-54.

25. Maruiti MR, Galdeano LE, Dias Farah OG. Anxiety and depressions in relatives of patients admitted in intensive care units. Acta Paul Enferm 2008;21:636-42.

26. Azoulay E, Pochard F, Kentish-Barnes N, et al. Risk of posttraumatic stress symptoms in family members of intensive care unit patients. Am J Respir Crit Care Med 2005;171:98794.

27. Tok $\mathrm{G}, \mathrm{Ok} \mathrm{G}$, Erbüyün $\mathrm{K}$, et al. Yoğun bakım ünitesinde yatan hastaların yakınlarında görülen anksiyete ve depresyon. Türk Yoğun Bakım Derneği Dergisi 2009;7:1-5.

28. Day A, Haj-Bakri S, Lubchansky S, et al. Sleep, anxiety and fatigue in family members of patients admitted to the intensive care unit: A questionnaire study. Critical Care 2013;17:R91.

29. Bolosi M, Peritogiannis V, Tzimas P, et al. Depressive and anxiety symptoms in relatives of intensive care unit patients and the perceived need for support. Journal of Neurosciences in Rural Practice 2018;9:522.

30. Demir K, Kaya Z, Kayrak M, et al. Orta yaş hipertansif bireylerde kan basıncı kontrolü ve uyku kalitesi arasındaki ilişkinin analizi. Selçuk Üniversitesi Tıp Dergisi 2011;27(2):837.

31. Johnson CC, Suchyta MR, Darowski ES, et al. Psychological sequelae in family caregivers of critically ill intensive care unit patients. A systematic review. Annals of the American Thoracic Society 2019;16:894-909.

32. Lee SY, Lee KA, Rankin SH, Weiss SJ, Alkon A: Sleep disturbance, fatigue, and stress among Chinese-American parents with ICU hospitalized infants. Issues Ment Health Nurs 2007; 28: 593-605.

33. Van Horn E, Tesh A. The effect of critical care hospitalization on family members: Stress and responses. Dimens Crit Care Nurs 2000;19:40-9. 